\title{
A System of Satellites Observing High Resolution Images Support in Road Traffic Environment
}

\author{
Yan WANG ${ }^{1, \text { a }}$, Hong ZHOU ${ }^{2, \mathrm{~b}}$, Hua XU ${ }^{3,4, \mathrm{c}}$, Zhonghua $\mathrm{HE}^{4, \mathrm{~d}, *}$, Liping $\mathrm{LEI}^{4, \mathrm{e}}$, Dandan CUI ${ }^{5, \mathrm{f}}$ \\ ${ }^{1}$ Highway Monitoring and Response Center \\ Ministry of Transport, China \\ ${ }^{2}$ Jiangsu Communications Holding Co., Ltd, China \\ ${ }^{3}$ School of Earth Sciences and Resources \\ China University of Geosciences \\ Beijing, China \\ ${ }^{4}$ Institue of Remote Sensing and Digital Earth \\ Chines Academy of Sciences, China \\ ${ }^{5}$ Beijing Digital Space Science and Technology Co., Ltd, China \\ E-mail: ${ }^{a} 1 w h j 98741 @ 126 . c o m$ \\ E-mail: bkgyyb@126.com \\ E-mail: cyoulingxuhua@163.com \\ *E-mail: dhezhonghua1992@163.com \\ E-mail: ${ }^{\mathrm{e}}$ leilp@radi.ac.cn \\ E-mail: ${ }^{\mathrm{f}}$ cuidd@dview.com
}

\begin{abstract}
With the need of road traffic monitoring and development of remote sensing technology, high resolution satellite images are valuable and available in traffic environment monitoring. We developed a system using the high resolution images observed by satellites combined with Geographic Information System (GIS) data, to support the monitoring of road traffic environment. In this paper, we present the overall structure and the database used in the system according to the functional and data requirements. In addition, we introduced all the function models and some experimental results. It is executable for road traffic information extraction in the experiment, including traffic jam monitoring, normalized congestion points, and the traffic environment. As a conclusion, this system can provide the serviceable information of road traffic environment using available high resolution satellite observing images to governmental decision-making department and the public.
\end{abstract}

Keywords-road traffic environment; high resolution image; road network monitoring

\section{INTRODUCTION}

Traffic incidents have been increasing in the highway and urban streets, which induced great economic loss, time waste and environmental pollution [1]. For that, the condition of traffic environment is highly concerned by the public and governments. It has important significance practically to monitor the road traffic status and its environment for formulating reasonable traffic control measures [2].

Even though, traffic condition over the city can be well analyzed with road side sensors and GPS trajectories [3]. As so far, we can't get the overall environmental information still by traditional traffic information capturing approach based on road side sensors, like induction loops, overhead sensors, video system and other timely detection equipment [4] which are difficult to conduct road traffic environment monitoring, including the timely traffic congestion, roads surrounding environment, spatial-temporal distribution of road status and so on. On the other hand, images from satellite observations, especially for the high resolution remote sensing images have been effectively applied in traffic status monitoring [5]. And more remote sensing satellite images with high space-time resolution are going to be available for traffic incidents monitoring, such as Gaofen-2 (GF-2) and Gaofen-4 (GF-4). GF-2 has a high spatial resolution of superior to $1.0 \mathrm{~m}$. Except for the medium wave infrared band with spatial resolution of $400 \mathrm{~m}$, the spatial and time resolution of GF-4 images are $50 \mathrm{~m}$ and $20 \mathrm{~s}$, respectively [6]. For each GF image, the size is up to around 1.0 GB or larger. It is necessary to build a system for high resolution satellite images applying in road traffic environment monitoring. Combining increasing road facilities and multiple monitoring technology such as remote sensing with visual serve system can be more effective in traffic problem controlling.

In this study, we established the network running road traffic monitoring system based on high resolution satellite observing images and GIS analysis tools. It was developed using geographic information system as the platform, and adopting ArcGIS Engine as a development tool. In addition, the regional road network in Beijing, China was working as a demonstration area for experiments. This visual system of the road traffic environment provides the information support for the traffic administrative department of traffic management organizations. At the same time, it can be alternative information for users travel decision and to ease the traffic congestion in a certain extent.

\section{OVERALL DESIGN OF SYSTEM}

The system is dedicated to provide visual information of road traffic environment for road operation evaluation by processing high resolution remote sensing images. In terms of research object, the system is mainly applied in traffic congestion status analysis, which can provide objective information support for traffic decision of 
government. Moreover, the functional system can be expanded according to the specific needs of users.

We adopted the plug-in structure for the system design. There are several advantages for the structure, including the different functional modules and user customization can be built according to different business functions or GIS functions, and a variety of database interface can be reserved that is convenient for the dataset sharing. In addition, we used the Client/Server (C/S) architecture model in the system. It provides service with advantages of high security, strong interactivity, low demand for network, and high speed. As shown in Figure 1, there are four main component subsystems for the system that include data acquisition subsystem, database and application environment, information processing subsystem and information output subsystem.

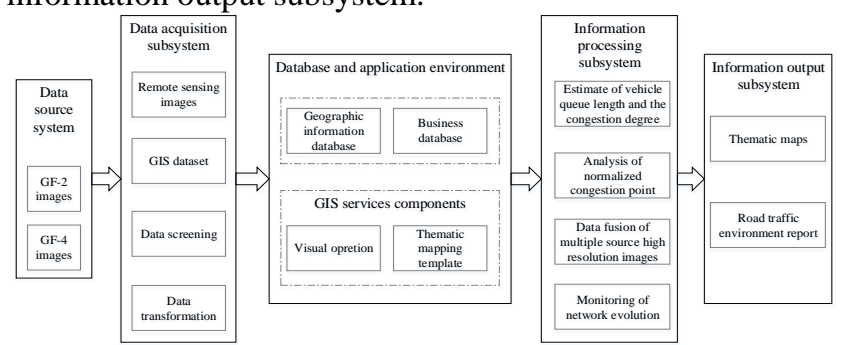

Figure 1. The overall frame of the system. Four main component subsystems are shown with external rectangular box.

\section{DATABASE ORGANIZATION}

The database design in the system include the design of spatial database, and attribute database. Spatial database include the background standard database, temporarily multi-temporal database, basically spatial database and temporary file database. And it was designed with ArcGIS Geodatabase.

At present, the spatial data planning of geographic information system (GIS) is based on the layer space. And geographic entities with similar characteristics are classed as one layer, such as normalized congestion points, road network distribution and administrative regions can be identified as point, line and polygon, respectively. In addition, attribute database is necessary for storing the information of the result of road network monitoring and thematic map template. Some attribute data tables, including the tables of monitoring result and thematic map are shown in Table 1 and 2.
TABLE I. ATTRIBUTE DATA TABLE OF MONITORING RESULT

\begin{tabular}{|c|c|c|c|}
\hline Number & Field name & $\begin{array}{c}\text { datatype } \\
\text { (Precision } \\
\text { range) }\end{array}$ & Discription \\
\hline 1 & ID & $\operatorname{Int}(20,0)$ & $\begin{array}{c}\text { Serial } \\
\text { number }\end{array}$ \\
\hline 2 & IMGNAME & Text(50) & Image name \\
\hline 3 & MONITORDATE & Date & $\begin{array}{c}\text { Moniyoring } \\
\text { time }\end{array}$ \\
\hline 4 & MONITORRANGE & Text(50) & $\begin{array}{c}\text { Moniyoring } \\
\text { scope }\end{array}$ \\
\hline 5 & MONITORRESULT & OLE object & $\begin{array}{c}\text { Moniyoring } \\
\text { result }\end{array}$ \\
\hline
\end{tabular}

TABLE II. ATTRIBUTE DATA TABLE OF THEMATIC MAP

\begin{tabular}{|c|c|c|c|}
\hline Number & Field name & $\begin{array}{l}\text { datatype } \\
\text { (Precision } \\
\text { range) }\end{array}$ & Discription \\
\hline 1 & ID & Number $(20,0)$ & $\begin{array}{c}\text { Serial } \\
\text { number }\end{array}$ \\
\hline 2 & THEMATICTYPEID & Number $(20,0)$ & $\begin{array}{c}\text { Type } \\
\text { number }\end{array}$ \\
\hline 3 & THEMATICMAPNAME & $\operatorname{Text}(30)$ & $\begin{array}{c}\text { Name of } \\
\text { thematic } \\
\text { map }\end{array}$ \\
\hline 4 & THEMATICMAPРATH & $\operatorname{Text}(50)$ & $\begin{array}{c}\text { Path of } \\
\text { thematic } \\
\text { map }\end{array}$ \\
\hline 5 & THEMATICMAPDATA & OLE object & $\begin{array}{c}\text { Data for } \\
\text { thematic } \\
\text { map }\end{array}$ \\
\hline 6 & CREATEUSER & $\operatorname{Text}(50)$ & $\begin{array}{c}\text { Username } \\
\text { of created } \\
\text { map }\end{array}$ \\
\hline 7 & CREARETIME & $\operatorname{Text}(50)$ & $\begin{array}{c}\text { Time of } \\
\text { created } \\
\text { map }\end{array}$ \\
\hline 8 & MODIFYUSER & $\operatorname{Text}(50)$ & $\begin{array}{l}\text { Username } \\
\text { of } \\
\text { modified } \\
\text { map }\end{array}$ \\
\hline 9 & MODIFYTIME & $\operatorname{Text}(50)$ & $\begin{array}{l}\text { Time of } \\
\text { modified } \\
\text { map }\end{array}$ \\
\hline
\end{tabular}

\section{FUNCTIONS OF SYSTEM AND REALIZATION}

The working process of the system can be included as below. Firstly, we collect the GF images including GF-2 and GF-4 and save them to the database. And then we conduct the analysis of vehicle image feature information. Based on the dataset of GF-2 and GF-4, and change detection method, we can achieve the traffic congestion status. Simultaneously, we can extract some road running index, such as road occupation, vehicle queue length and so on, based on the high resolution satellite images and road and vehicle extraction techniques. 


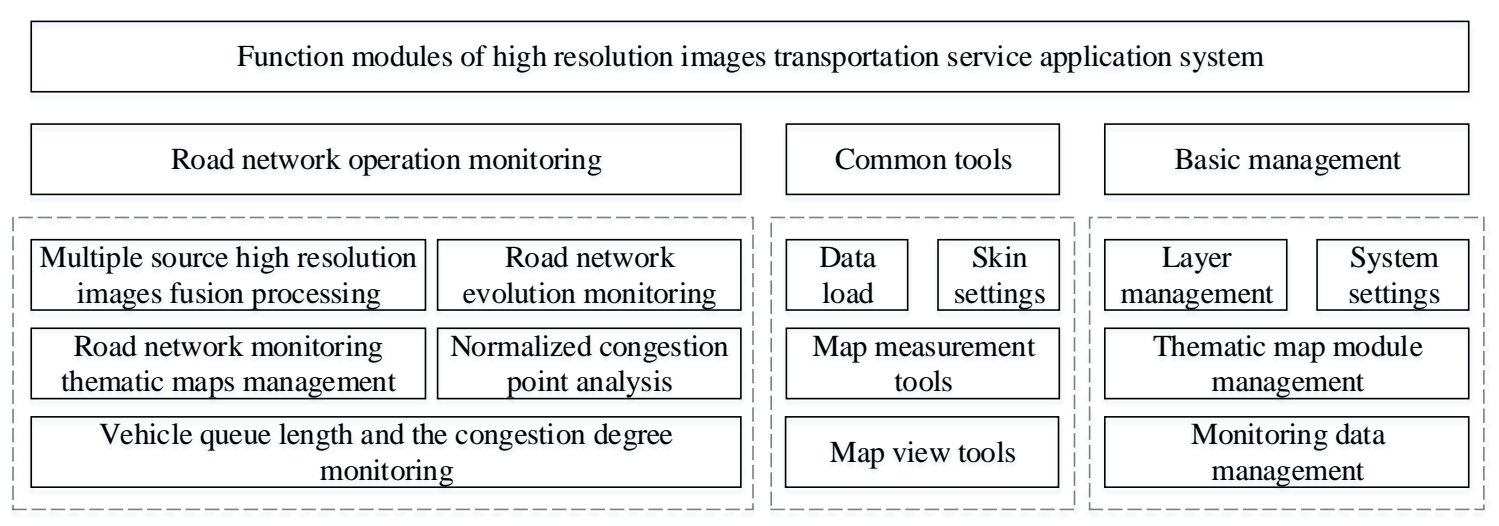

Figure 2. The functional modules of the system. And three parts including basic management, common tools and network operation monitoring is summarized.

As shown in Figure 2, the function models can be separated into three parts. That include the main research content, road network operation monitoring, and two basic models, including common tools and basic management. For the main research content, we realized five major functions. The first one, vehicle queue length and the congestion degree monitoring, it is using the ratio analysis model to determine the traffic jam section in a certain period, based on the selected target image and the background image. The second one, normalized congestion analysis, we analysis the congestion points and indicated with different color, based on selected scope and prescribed time period. The third one, road network monitoring thematic maps management, we provide management of the thematic map products, including road congestion degree thematic map products and normalized congestion point of thematic map. The fourth one, road network evolution monitoring, we provide the analysis and demonstration of multi-temporal thematic maps. The fifth one, multiple source high resolution images fusion processing, we provide a professional model for regional image fusion, based on the selected multispectral image data and corresponding panchromatic image. And some common tools and basic management functions were added in the system for better implementing of the road traffic environment monitoring.

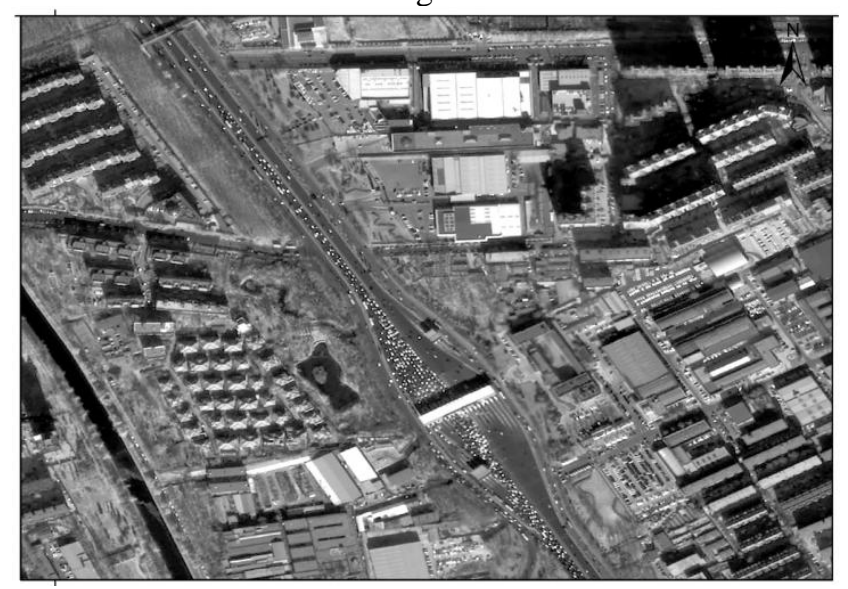

Figure 3. Road traffic information viewed from satellite images. Vehicles show white spots over the highway. And the side roads and buildings around the highway can be identified.

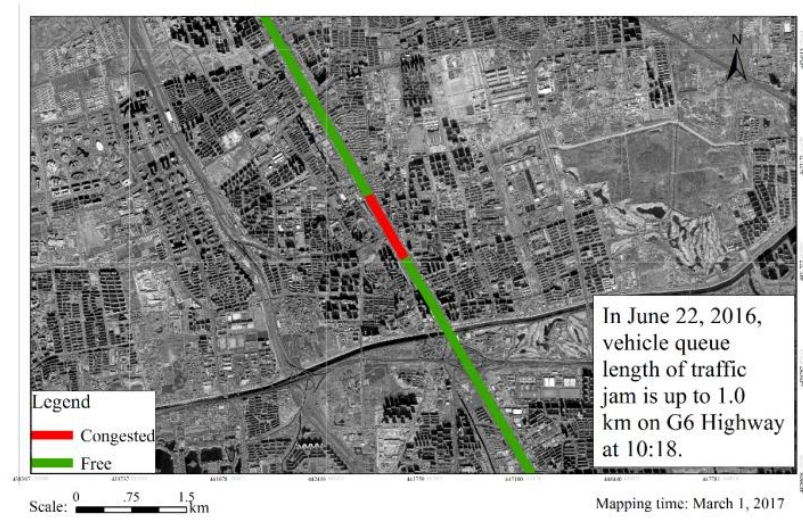

Figure 4. Output thematic map of vehicle length and the congestion degree of a section n G6 Highway in Beijing from this system. Red line and green line represent the section of congested and free, respectively.

And the time and location of the traffic jam is described in the box shown in the bottom right corner.

Road traffic information can be well captured in high resolution satellite images as shown in Figure 3 (One section of the G6 Highway in Beijing). Based on the high resolution images and related algorithm in the system, vehicle queue length and the congestion degree can be identified as shown in Figure 4. Using multi-temporal images, we can achieve the normalized congestion points as shown in Figure 5, based on traffic jam analysis and data statistic in the system. The functions mentioned above are basically running in the system with data of high resolution satellite images and GIS data. And the results are exported with thematic maps like Figure 4 and 5. 


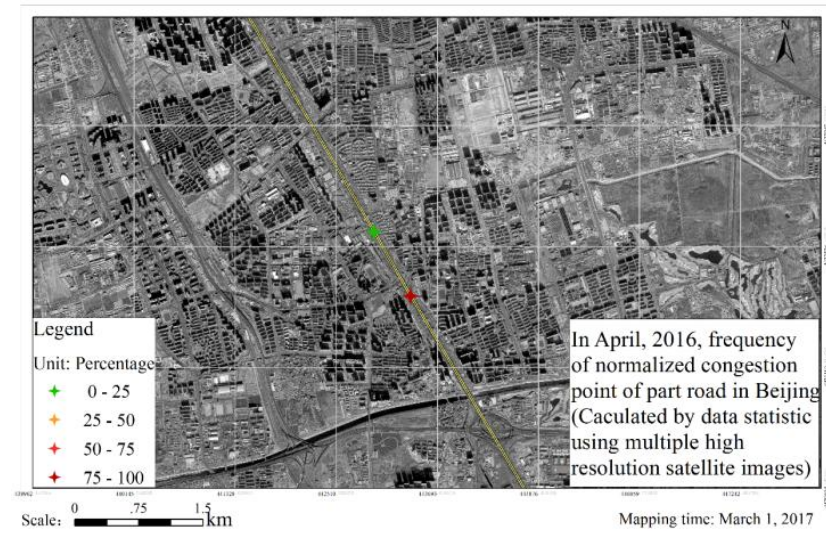

Figure 5. Output thematic map of normalized congestion points in a section of G6 Highway in Beijing from the system. The red cross dot represent severe normalized congestion point with probability lager than $75 \%$. And the probability shown with green cross dot is within $0-25 \%$. The time and location of the statistic is shown in the box of bottom right corner.

\section{CONCLUSION}

We developed a system for high resolution satellite images applying on road traffic environment, based on ArcGIS Engine. It provides several interface for integrated application of remote sensing images and GIS information. Users can perform a variety of road traffic environment monitoring functions, according to their needs. In addition, for raising the efficiency of data processing of large volume of image data, real-time automatic operation can be conducted in the system. Road traffic information extraction processing will be carried on automatically, and users can achieve the thematic maps directly, when image data are obtained and imported into the system. This system could be an alternative tool for emergency application of road traffic problems in a large festival holiday, the specific activity and disaster emergency conditions, with available high resolution satellite images.
Although, it is efficient for the experiment result in road traffic environment monitoring, the completion of the overall system still need to be further improved. There are still some issues that need to be better considered, such as the robustness of the system in processing large amount of remote sensing images, and the algorithm in dealing with a variety of different situations. Eventually, it could work more effectively in dealing with road network incidents for providing valuable spatial and temporal information of road traffic environment, with the improvement of the functions and algorithms.

\section{ACKNOWLEDGEMENTS}

The work was supported by the project of "Grand Special of High resolution On Earth Observation: Application demonstration system of high resolution remote sensing and transportation", Grant No.07-Y30B10-9001-14/16.

\section{REFERENCES}

[1] B. Pan, U. Demiryurek, C. Shahabi, and C. Gupta, IEEE 13th International Conference on Data Mining, Forecasting Spatiotemporal Impact of Traffic Incidents on Road Networks, (2013), p. 587-596.

[2] O. Oviedo-Trespalacios, M. Mazharul Haque, M.J.King and S Washington, International Driver Distraction and Inatten Conference, Influence of Road Traffic Environmrnt and Mobile Phone Distraction on the Speed Selection Behaviour of Young Drivers, (2015), p.1-12

[3] Z. Wang, M. Lu, X. Yuan, and J. Zhang, IEEE Transactions on Visualization \& Computer Graphics "Visual Traffic Jam Analysis Based on Trajectory Data,", Vol. 19 (2013), p. 2159-2168.

[4] P.-T. Chen, F. Chen, and Z. Qian, IEEE International Conference on Data Mining, Road Traffic Congestion Monitoring in Social Media with Hinge-loss Markov Random Fields, (2014), p.80-89

[5] S. O. Larsen, H. Koren, and R. Solberg, Photogrammetric Engineering and Remote Sensing, Traffic Monitoring Using Very High Resolution Satellite Imagery, (2009), p.75

[6] Information on http://www.cresda.com/EN/satellite/9907.shtml 